\title{
Reliability Analysis of Power Distribution System
}

\author{
Khaidir Ali ${ }^{1}$, Rama Okta Wiyagi ${ }^{2}$, Ramadoni Syahputra ${ }^{* 3}$ \\ ${ }^{1,2,3}$ Department of Electrical Engineering, Universitas Muhammadiyah Yogyakarta \\ J1 Lingkar Selatan Tamantirto Kasihan Bantul, (0274)387656 \\ *Corresponding author, e-mail: ramadoni@umy.ac.id
}

\begin{abstract}
Electrical distribution system is a component of electrical power system that is very important because it is closest to the customer. In its operation, the distribution system often suffers that causes the flow of electricity to the customer is interrupted. This situation is not expected by customers or by electric power companies. The more frequent and longer the occurrence of electrical power flow interruption, the lower the system reliability, and vice versa. Reliability of a distribution system can be analyzed based on SAIDI and SAIFI parameters. In this research, reliability analysis of distribution system on Gejayan substation. The analysis result using SAIDI and SAIFI parameters shows that Gejayan substation is reliable enough to national standard, while based on international standard still not reliable. Copyright (C) 2017 Universitas Muhammadiyah Yogyakarta- All rights reserved.
\end{abstract}

Keywords: Distribution system, SAIDI, SAIFI, system reliability

\section{Introduction}

Electricity is a basic necessity that is not released from every activity of society. Electricity energy utilized by the community is generated from power plants powered by various power plants such as steam power plants, hydroelectric power, gas power plants, diesel power plants, and nuclear power plants [1]-[4]. Electric power utilized by the society in Indonesia is provided by PT PLN (Persero) as a provider of electricity, therefore PT PLN (Persero) also has a quality target in the distribution of electrical energy so that electricity can be channeled with good continuity and the frequency of blackouts that minimum [5]. Not only the quality, the reliability of the network becomes an important aspect in the distribution of electrical energy to customers, so to achieve it, then a good protection system must be met [6].

An electrical power system, the level of which is very important in determining the performance of the system. This can be seen from where can supply continuously in one year. The most fundamental problems in the distribution of electrical power are in quality, continuity and power [7]-[11]. Disturbances that occur in units of generation will cause disruption of electricity supply with all the consequences for electricity companies and consumers.

It needs to be a concern number of disturbances that occur on. Currently, of course, can affect in the distribution of electrical energy. This can be known by standards that are in accordance with predefined standards [12]. Therefore, the parameters that can be used as reference in calculating the clarity of energy by calculating the average index of system interference with SAIFI (System Average Interruption Frequency Index), the average duration index of system interruption during the season is SAIDI (System Interruption Period Length (CAIDI) (Average Customer Interruption Duration Index), ASAI (Index of Average System Availability), ASUI (Index of Elements of No System Attendance). Therefore, the quality of electrical energy distribution will assess both the frequency of blackouts that occur as small as possible and the duration of its outage as soon as possible [13]-[17].

Potential of energy in Kalasan and Yogyakarta city (North and South of Yogyakarta) is where the electricity supply for Yogyakarta City and its surrounding area is done by PT PLN (Persero) APJ Yogyakarta - Rayon Kalasan and Rayon Yogyakarta through Gejayan Substation. Gejayan 
Substation serves the needs for various business sectors and services. In this research will be analyzed quantity and duration of disturbance at each feeder in Gejayan Substation, Yogyakarta.

\section{Reliability of Distribution System}

\subsection{Reliability Analysis}

The reliability of electric power distribution system plays an important role in the comfort and security for both corporate and household consumers [18]. The reliability index is a method of evaluating the reliability parameters of a power distribution equipment on the reliability of the quality of service to the customer. These indexes include SAIDI (System Average Interruption Duration Index), SAIFI (System Average Interruption Frequency Index).

Saodah [2] conducted a study on the Evaluation of Power Distribution System Reliability Based on SAIDI and SAIFI. In his research described about SAIDI and SAIFI that both of these are reliability indices that can determine whether the system is stated as expected or not. In the research it can be concluded that the number of interference in medium-voltage air distribution system (SUTM) $61.36 \%$ caused by releases work without obvious cause so that PMT can work again. Then this data is also obtained from the processing and calculation of data disturbance, blackout data, and customer data based on SAIDI and SAIFI index.

Yaom [3] conducted research on Reliability Analysis of Power Distribution System at PT. PLN UPJ Rayon Bumiayu, explains that there are only two repeats that have reliable SAIFI and SAIDI values. This means that in every substation must be analyzed to find out how big the value of reliability, because it affects the quality of electricity provided to customers. In his research it can be concluded that some repeater on the Tambun substation does not meet the standard of reliability index. Six feeders are categorized less reliable because the SAIFI value is greater than the IEEE standard, while four feeders are categorized as less reliable because the SAIDI value is greater than the IEEE value standard. Then the value of rayon performance is also still less reliable because there are some rayon in Gejayan Substation that has not met the standard of WCS (world class service) and WCC (world class companies).

\subsection{Distribution System}

Generally, the power plant is located far from the load center, especially the large-scale power plant, so to distribute the power to the consumer or the load center, the power must be channeled. Distribution network system can be divided into 2 primary distribution network system and secondary distribution network system [19]. Both systems are differentiated by their working voltage. In general, the working stress on the primary distribution network system is $20 \mathrm{kV}$, while the working voltage on the secondary distribution network system is 380 $\mathrm{V}$ or $220 \mathrm{~V}$ [20].

To supply power continuously and reliably, the selection of appropriate distribution system is needed. The selection criteria are based on several factors, including economic factors, location, and feasibility. Selection of network system must meet the criteria of requirements are [21]:
a. High reliability
b. Continuity of service
c. Low investment cost
d. Low frequency and voltage fluctuations

The primary distribution network system is part of the power system between the Substation and the Distribution Substation. This primary distribution network generally consists of a three-phase network, which is three wires or four wires. The voltage drop of this system from the transmission voltage is first performed on the sub-transmission substation, where the voltage is lowered to a lower voltage from the $500 \mathrm{kV}$ voltage system to the 150 $\mathrm{kV}$ voltage system or to the $70 \mathrm{kV}$ system voltage, then to the re-distribution substation $20 \mathrm{kV}$.

The primary distribution network system used to channel the electrical power at each load is called a feeder. In general, each repeater is named according to the loaded area served. It aims to make it easier to remember and mark the paths served by the feeders [22].

The secondary distribution network is part of the primary distribution network where the network is directly connected with the consumer of electric power. In the secondary distribution network, the primary distribution voltage system of $20 \mathrm{kV}$ is lowered to a low voltage system of $380 / 220 \mathrm{~V}$.

The number of repeaters in a region / area is generally more than one repeater. The larger and complex loads served in a region / region, the more the number of repeaters needed. Some repeats are assembled at a point called Hose. Subway is an installation of electrical equipment that serves as: 
1. Collecting points of one or more sources and feeders.

2. Place the transfer (transfer) load in case of interference on one of the network served.

Combined multiple feeders can form several types of primary distribution network systems. Based on the shape or pattern, the type of primary distribution network system can be divided into four, namely:

1. Radial system

2. Circular system (loop / ring)

3. Spindle system

4. Cluster system (mesh)

The security system aims to prevent, limit or protect networks and equipment against the danger of damage caused by interference with both temporary and permanent disturbances so that the quality and reliability of electric power distribution expected by consumers can be guaranteed properly. $20 \mathrm{kV}$ medium voltage network safety system is a very important component designed to secure. Medium voltage network and equipment and serves to carry a limited electric current to be supplied by the distribution transformer. In general, the safety equipment contained in the medium voltage distribution network system are: Power Breaker, Disconnecting Switches, Automatic Sequence Switch (SSO), Load Switch (SB), Fuser, and Arrester.

Disturbance in the distribution system is the disruption of the electrical system that causes the work of the repeater safety relay works to open the circuit breaker at the substation causing the dissolution of the power supply. This is to secure the equipment through which the interference flow to from damage. So the function of the safety equipment is to prevent equipment damage and not to nullify interference.

Disturbances in the distribution network are more prevalent in the free-flow distribution channels generally do not use isolation compared to the distribution channels grown in the soil by using insulating wrappers. Source of interference in the distribution network can come from within the system or from outside the distribution system.

Reliability in a distribution system is a measure of the availability / level of electricity supply service from system to user / customer. The size of reliability can be expressed as how often the system goes into blackouts, how long the blackout occurs and how fast it takes to recover from the outage.

The reliability of the distribution network system is closely related to the problem of termination of the load (blackout) due to a system interruption. In this case, the reliability of the distribution system is inversely proportional to the level of load termination (blackout) on the system. The higher the level of load termination, the reliability will decrease. Vice versa. Systems that have high reliability will be able to provide power at any time needed, while the system has a low reliability when the low availability of power is often extinguished.

The application of the concept of distribution system reliability differs from the application of the generation system and the transmission system, whereby the distribution system is more oriented to the customer's load point rather than the orientation of the system, and the local distribution system is considered more than a broadly integrated system that includes generating and transmission facilities. The reliability of transmission and transmission systems takes into consideration the probability of loss of load, with little regard for system components, whereas distribution reliability looks at all aspects of engineering, such as design, planning, operation. Since the distribution system is less complex than the integrated generation and transmission systems, the mathematical probability calculations are simpler than those required for the assessment of transmission and generation reliability.

Reliability is the performance of a device or system in accordance with its function within a certain period of time and operating conditions. The various levels of reliability in service can be divided into 3 (three) things, among others:

\section{High system reliability}

Under normal conditions, the system will provide sufficient capacity to provide power at peak loads with good voltage variation and in an emergency when there is interference with the network, then this system of course required some equipment and safety enough to avoid the existence of various kinds of interference on the system.

\section{Medium system reliability}

Under normal conditions the system will provide sufficient capacity to provide power at peak loads with good voltage variation and in an emergency in case of interference with the network, the system can still serve part of the load even under peak load conditions. So in this system required a lot of equipment to overcome and overcome these disorders.

\section{Low system reliability}


Under normal conditions the system will provide sufficient capacity to provide power at peak loads with good voltage variation, but if a system interference occurs the system could not at all serve the load. So it needs to be fixed first. Of course, on this system the safety equipment is relatively very few in number.

\section{Research Methodology}

In this research there are several steps work done to achieve the desired end result according to the flow diagram as can be seen in Fig. 1.

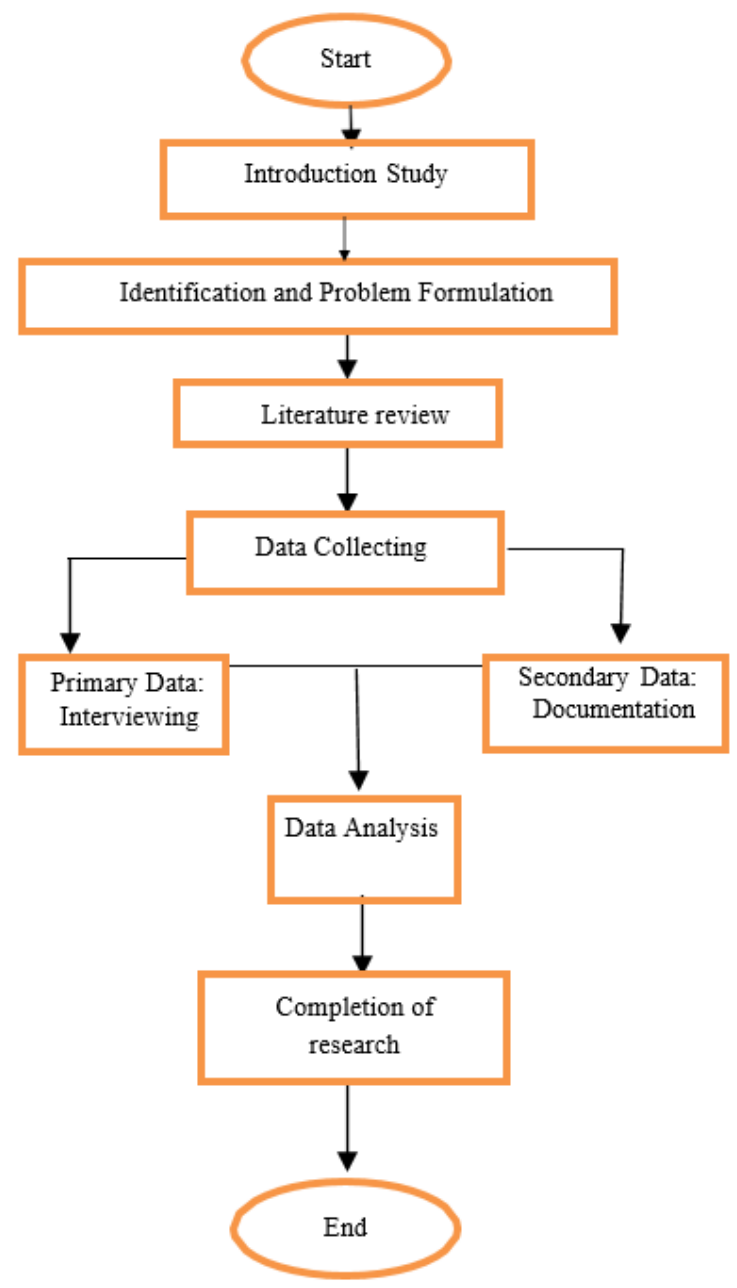

Fig.1 Flow Chart of the research

To give a clearer picture then below is given a more thorough explanation of each of the research steps:

1. Introduction Study

A preliminary study is an early stage in the writing methodology. At this stage the study and observation in the field directly to perform data collection in PT.PLN Area Yogyakarta.

2. Identification and Problem Formulation.

After a preliminary study, problems in the area of electricity distribution system of Gejayan Substation can be identified. Then the cause of the problem can be traced. In tracing the root cause of the problem, it is done through data collection on electricity distribution system. In this research, the problem raised to the topic is Reliability Analysis of Power Distribution System in Gejayan Substation, especially on every feeder $20 \mathrm{kv}$ in Gejayan Substation.

\section{Library Studies}

Literature study was conducted to obtain references related to research to find information about the theory of SAIDI, SAIFI, CAIDI, electric power transmission system, power distribution system, component on substation, reliability of power distribution system $20 \mathrm{kv}$, standard value reliability indexes, methods, and concepts relevant to the problem. So that with the information can be used as a reference in solving the problem.

\section{Data Collection}

Type of data in this research there are 2 (two) kinds, that is primary data and secondary data. Primary data is data obtained from the results of the study and direct observation of the object of research. One of the methods used to obtain primary data is interview (interview) while in the field. The following primary data required in this research is the amount of power transformer and capacity of each transformer on the Gejayan 150 KV Substation and the number of feeder $20 \mathrm{kv}$ on the 150 kv Gejayan Substation.

Secondary data collection is done directly at PT. PLN APJ Area Yogya. The purpose of this data collection is to obtain data relating to research of final project which will analyze how reliable $20 \mathrm{kv}$ power distribution system in each feeder $20 \mathrm{kv}$ on Gejayan Substation. The following data required as documentation is the number of subscribers supplied by the Gejayan 150kv Substation and the data of each feeder $20 \mathrm{kv}$ Substation of $150 \mathrm{kv}$ Gejayan.

\section{Data Analysis}

Based on the data obtained in this research, will be analyzed to get the value of SAIDI, SAIFI and CAIDI to find out how much reliability level realization of power distribution system on each feeder $20 \mathrm{kv}$ in $150 \mathrm{kv}$ Gejayan and compare the standard value of reliability index which is used in this thesis research. Standard index values used are 
IEEE std 1366-2003, world-class company standard (WCC) and world class service (WCS), SPLN 68-2: 1986 and target PT. PLN Rayon Kalasan, Rayon North Yogyakarta and Rayon South of Yogyakarta in 2015.

\section{Improving the Manuscript}

After completion of data processing and data analysis the next step is to compile the final project with the standard rules.

\section{Results and Discussion}

\subsection{SAIFI of Gejayan Substation}

The data of the feeder disruption for one year by 2015 includes data:

1. Time for Outage (Extinction)

2. Entry Time (On)

3. Duration of Outage

From these data it will be known how long the duration of outages and the frequency of outages on each feeder. In the calculation of duration will be known in time in units of minutes, while the failure rate will only calculate the total number of trips or turns off each feeder in 2015. Below is a table of data disturbance disturbers Gejayan Substation in 2015 .

There is a little note that on the duration of the disturbance data in GJN 02 and GJN 03 sufferer miscalculation. The Microsoft Excel application is not precise and accurate in understanding the clock calculations in day shifts. Calculations performed by PLN (Persero) is to reduce the time of flame with time off, so the result of the time difference will be used as the duration of the occurrence of power outages. However, the Microsoft Excel application misunderstood its calculation time. It should calculate the duration of the outage of the electric current counterclockwise clockwise in the day, but the repeater GJN 02 and GJN 03 clockwise in one day so that the duration of the results obtained is very large. The solution of this problem is to perform manual calculations on GJN 02 and GJN 03 feeders in January of 2015.

Here is the comparison of SAIFI value calculation of Gejayan Substation in feeder of Kalasan area as shown in Figure 2.

The GJN 19 feeder as shown in Fig. 2 illustrates that in an area in which electricity is powered through a GJN 19 repeater has the most disturbance problems, so the reliability level based on the lower SAIFI value is due to the number of disturbances. This is due to the fact that the power consumption is high enough and the number of consumers that much so that the occurrence of Overload. When compared with other feeder in Kalasan area, then the disturbance that occurs at most due to internal factors such as overload. From the calculation of SAIFI value on Gejayan Substation feeder in Rayon Kalasan, SAIFI value can be categorized less reliable if it refers to standard of SAIFI value according to SPLN No. 6821986 which is 3.2 times / customer / year. For international standards used i.e. IEEE stdb13662003 which has a standard value of SAIFI that is 1.45 times / customer / year, Gejayan Substation feeder located in Kalasan area, there is one repeater that is categorized as less reliable that is GJN 19 repeater, because its SAIFI value greater than the IEEE value standard. Repeater GJN 02 and feeder GJN 18 are categorized as reliable because they have SAIFI value 0,447 times / customer / year (GJN 02) and 0.898 times / customer / year (GJN $18)$.

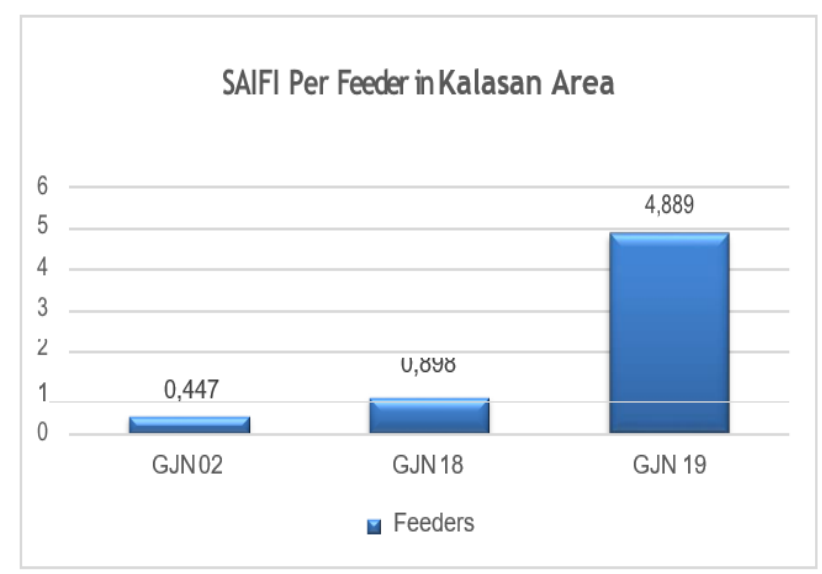

Fig. 2. SAIFI per feeder in Kalasan Area

The performance of PLN Rayon Kalasan if the total of all the existing feeders in the Gejayan Substation has a SAIFI value of 6,264 times / customer / year is categorized as reliable because it meets the target value of SAIFI PLN Rayon Kalasan is 7.75 times / customer / year. The performance value of SAIFI PLN Rayon Kalasan is still less reliable because it is bigger than SAIFI grade world class service (WCS) and world class company (WCC) that is 3 times / customer / year.

Here is the comparison of SAIFI value calculation of Gejayan Substation in feeder of Yogyakarta City area as shown in Figure 3. 


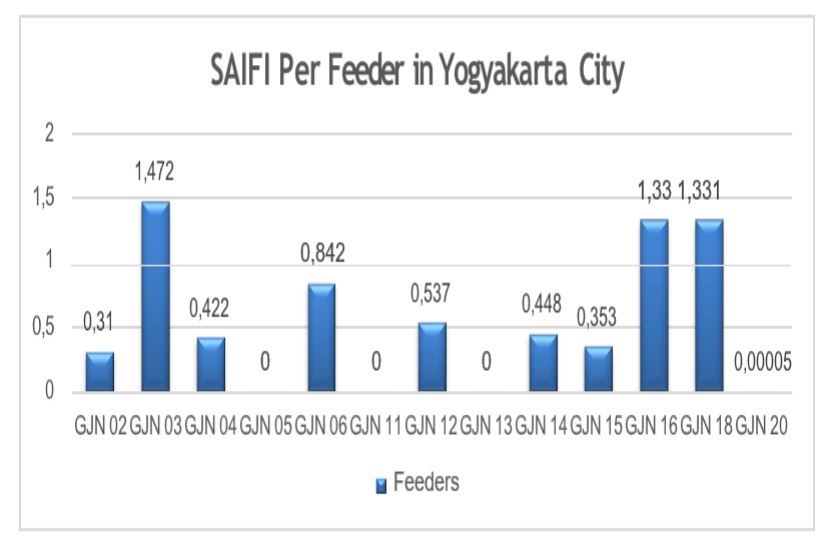

Fig. 3. SAIFI per feeder in Yogyakarta City Area

Feeders GJN 03, GJN 16 and GJN 18 as shown in Figure 3, explains that in areas with electrical power through repeater GJN 03, 16 and 18 have the most disturbance problems. The reliability level based on the lower SAIFI value is due to the number of disturbances. This is due to the fact that the power consumption is high enough and the number of consumers that much so that the occurrence of Overload. When compared with other repeater in Rayon Yogya, then the disturbance that happened at most because of internal factor like overload. This factor is reinforced by the presence of high-reliability repeaters, such as GJN, 05, 11 and 13 . Very rarely, interference caused by external factors.

From the calculation of SAIFI value on Gejayan Substation feeder in Yogyakarta area, SAIFI value can be categorized as reliable when referring to SAIFI standard value according to SPLN No. 68-2 1986 which is 3.2 times / customer / year. For international standards used ie IEEE std 1366-2003 which has a standard value of SAIFI that is 1.45 times / customer / year, Gejayan Substation feeder located in Rayon Yogyakarta there is one repeater that is categorized as less reliable that is GJN 03, because its SAIFI value greater than the standard value of IEEE std 1366-2003. Feeders GJN 05, GJN 11 and GJN 13 Repeater is categorized as very reliable because it has SAIFI value 0 times / customer / year.

Performance of PLN Yogyakarta area is totaled from all feeders in Gejayan Substation has a value of SAIFI 7.04505 times / customer / year. It has been categorized less reliable because its SAIFI value is bigger than target of SAIFI value of PLN Rayon Yogyakarta which is 6.98 times / year. The performance value of SAIFI PLN Yogyakarta area is still less reliable because it is bigger than SAIFI grade world class service (WCS) and world class company (WCC) 3 times / customer / year.

\subsection{SAIDI of Gejayan Substation}

Here is the comparison of the calculation of the value of SAIDI for feeders of Gejayan Substation in Kalasan area as shown in Figure 4.

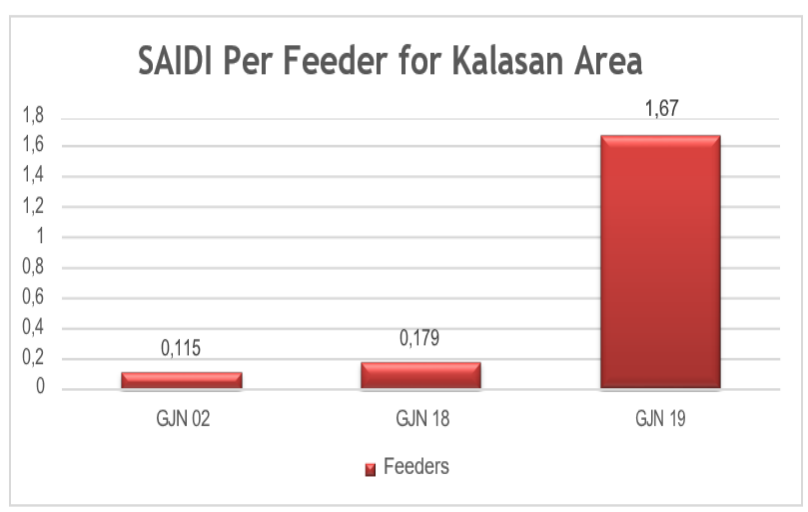

Fig. 4. SAIDI per feeder in Kalasan Area

The GJN 19 feeder as shown in Fig. 4 illustrates that in an area in which electricity is supplied via a GJN 19 receptacle it has the most interference problem, so the reliability level based on the lower SAIDI value is due to the number of disturbances. This is because of the factor of electricity consumption is high enough and the number of consumers that much so that the overload. When compared with other repeater in Rayon Kalasan, the disturbance that occurs most due to internal factors such as overload.

From the calculation of SAIDI value on Gejayan Substation feeder in Rayon Kalasan, SAIDI value can be categorized as reliable when referring to SAIDI standard value according to SPLN No. 68-2 1986 which is 21.09 hours / customer / year. For international standard used i.e. IEEE std 1366-2003 which has SAIDI standard value 2,3 hours / customer / year, Gejayan Substation feeder located at Rayon Kalasan can be categorized reliable because its SAIDI value has complied with IEEE value standard.

The performance of PLN Rayon Kalasan if the total of all the existing feeders in Gejayan Substation has a value of 1.964 hours / customer / year is categorized as reliable because it is smaller than the target value of SAIDI PLN Rayon Kalasan is 8.65 hours / customer / year. Performance of SAIDI in PLN Rayon Kalasan is still less reliable, because it is bigger than world class service world class service (WCS) and world class company 
(WCC) standard that is 1.666 hours / customer / year.

Here is the comparison of the calculation of the value of SAIDI for feeders of Gejayan Substation in Yogyakarta city area as shown in Figure 5.

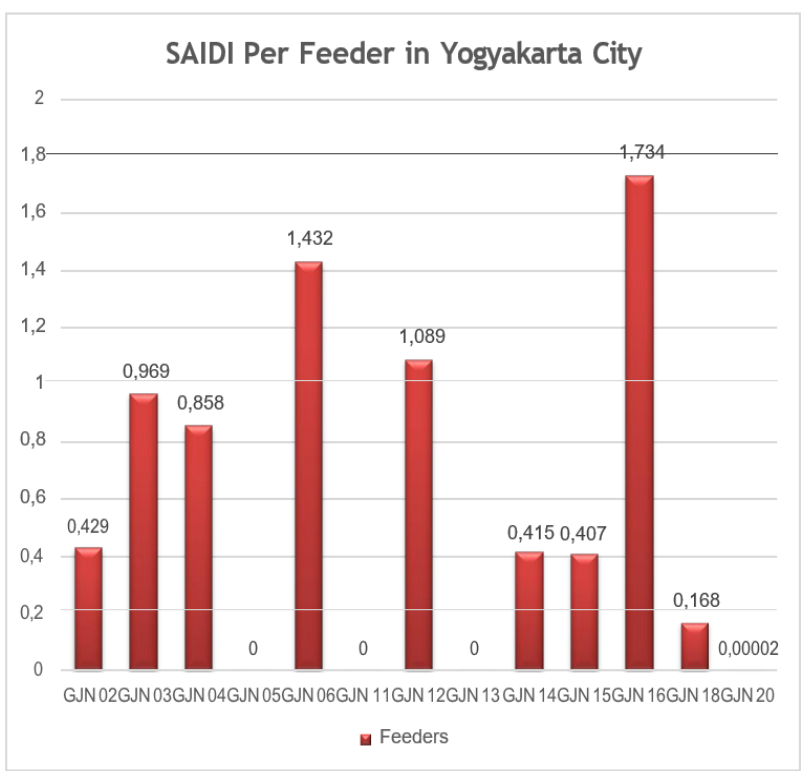

Fig. 5. SAIDI per feeder in Yogyakarta City Area

The GJN 16 feeder, as shown in the Figure 5, explains that in areas where electricity is supplied through a repeater GJN 16 has the most disturbing problems, so the reliability level based on lower SAIDI values is due to the number of disturbances. This is due to the fact that the power consumption is high enough and the number of consumers that much so that the occurrence of Overload. when compared with other repeater in Rayon Yogya, then the disturbance that happened at most because of internal factor like overload. Then the GJN 16 repeater has a long duration of interruption. When calculated using the SAIDI formula, the largest bar graph on the highest GJN 16. SAIDI formula is based on the duration of the disturbance.

From the calculation of SAIDI value on the feeder of Gejayan Substation in Rayon Yogya, SAIDI value can be categorized as reliable if it refers to SAIDI standard value according to SPLN No. 68-2 1986 which is 21.09 hours / customer / year. For the international standard used ie IEEE std 1366-2003 which has SAIDI standard value 2.3 hours / customer / year, Gejayan Substation feeder located in Rayon Yogyakarta can be categorized as reliable because its SAIDI value is smaller than standard of IEEE value.

The performance of PLN Rayon Yogya if it is totaled from all the existing feeders in Gejayan
Substation has a value of 7.501 hours / customer / year is categorized as reliable because it is smaller than the target value of SAIDI PLN Rayon Yogya which is 8.10 hours / customer / year. The performance value of SAIDI PLN Rayon Yogya is still far less reliable, because it is bigger than world class service world class service (WCS) and world class company (WCC) standard which is 1.666 hours / customer / year.

\section{Conclusion}

The value of SAIFI and SAIDI on the Gejayan Substation feeder located in the working area of two rayon, Rayon Kalasan and Rayon Yogya can be categorized as less reliable than the SAIFI and SAIDI value standard according to SPLN No. 68-2 1986, SAIFI 3.2 times / customer / year and SAIDI 21.09 hours / customer / year. SAIFI value at one rayon is Rayon Kalasan categorized reliable because its SAIFI value is smaller than standard value according to SPLN No. 68-2 1986. For international standard used ie IEEE std 1366-2003 which have standard value SAIFI that is 1,45 times / customer / year, the GJN 19 and GJN 03 feeders are categorized less reliable because the SAIFI value is greater than the IEEE standard. For the international standard used ie IEEE std 1366-2003 which has SAIDI standard value 2,3 hours / customer / year, all repeater in Rayon Kalasan and rayon Yogya is categorized as reliable because SAIDI value is smaller than IEEE value standard.

\section{References}

[1] Allen Short, T. 2014. Electric Power System Distribution Handbook Second Edition. USA: CRC Press.

[2] Saodah, S. 2008. Evaluasi Keandalan Sistem Distribusi Tenaga Listrik Berdasarkan SAIDI dan SAIFI (Jurnal). Yogyakarta.

[3] Fajar, A. 2015. Analisis Keandalan Sistem Distribusi Tenaga Listrik DI P.T. PLN UPJ Rayon Bumiayu (Skripsi). Yogyakarta: Universitas Muhammadiyah Yogyakarta.

[4] Marsudi, D. 2005. Operasi Sistem Tenaga Listrik. Jakarta: Balai Penerbit dan Humas ISTN.

[5] IEEE Std. 1366-2012. 2012. IEEE Guide for Electric Power Distribution Reliability Indices. USA.

[6] Syahputra, R., Robandi, I., Ashari, M. (2015). Performance Improvement of Radial Distribution Network with Distributed Generation Integration Using Extended Particle Swarm Optimization Algorithm. International Review of Electrical Engineering (IREE), 10(2). pp. 293-304. 
[7] Syahputra, R., Robandi, I., Ashari, M. (2015). Reconfiguration of Distribution Network with DER Integration Using PSO Algorithm. TELKOMNIKA, 13(3). pp. 759-766.

[8] Syahputra, R., (2012), "Distributed Generation: State of the Arts dalam Penyediaan Energi Listrik", LP3M UMY, Yogyakarta, 2012.

[9] Syahputra, R., (2016), "Transmisi dan Distribusi Tenaga Listrik", LP3M UMY, Yogyakarta, 2016.

[10] Syahputra, R., (2015), "Teknologi dan Aplikasi Elektromagnetik", LP3M UMY, Yogyakarta, 2016.

[11] Syahputra, R., Robandi, I., Ashari, M. (2014). Optimization of Distribution Network Configuration with Integration of Distributed Energy Resources Using Extended Fuzzy Multi-objective Method. International Review of Electrical Engineering (IREE), 9(3), pp. 629-639.

[12] Syahputra, R., Robandi, I., Ashari, M. (2014). Performance Analysis of Wind Turbine as a Distributed Generation Unit in Distribution System. International Journal of Computer Science \& Information Technology (IJCSIT), Vol. 6, No. 3, pp. 39-56.

[13] Syahputra, R., (2013), “A Neuro-Fuzzy Approach For the Fault Location Estimation of Unsynchronized Two-Terminal Transmission Lines", International Journal of Computer Science \& Information Technology (IJCSIT), Vol. 5, No. 1, pp. 23-37.

[14] Syahputra, R., (2012), "Fuzzy Multi-Objective Approach for the Improvement of Distribution Network Efficiency by Considering DG", International Journal of Computer Science \& Information Technology (IJCSIT), Vol. 4, No. 2, pp. 57-68.

[15] Syahputra, R., Soesanti, I. (2015). "Control of Synchronous Generator in Wind Power Systems Using Neuro-Fuzzy Approach", Proceeding of International Conference on Vocational Education and Electrical Engineering (ICVEE) 2015, UNESA Surabaya, pp. 187-193.

[16] Syahputra, R., Robandi, I., Ashari, M. (2014). "Optimal Distribution Network Reconfiguration with Penetration of Distributed Energy Resources", Proceeding of 2014 1st International Conference on Information Technology, Computer, and Electrical Engineering (ICITACEE) 2014, UNDIP Semarang, pp. 388 - 393.

[17] Syahputra, R., Robandi, I., Ashari, M., (2013), "Distribution Network Efficiency Improvement Based on Fuzzy Multi-objective Method". International Seminar on Applied Technology, Science and Arts (APTECS). 2013; pp. 224-229.

[18] Syahputra, R., Robandi, I., Ashari, M., (2012), "Reconfiguration of Distribution Network with DG Using Fuzzy Multi-objective Method", International Conference on Innovation, Management and
Technology Research (ICIMTR), May 21-22, 2012, Melacca, Malaysia.

[19] Syahputra, R. (2010). Fault Distance Estimation of Two-Terminal Transmission Lines. Proceedings of International Seminar on Applied Technology, Science, and Arts (2nd APTECS), Surabaya, 21-22 Dec. 2010, pp. 419-423.

[20] Syahputra, R., Soesanti, I. (2015). Power System Stabilizer model based on Fuzzy-PSO for improving power system stability. 2015 International Conference on Advanced Mechatronics, Intelligent Manufacture, and Industrial Automation (ICAMIMIA), Surabaya, 15-17 Oct. 2015 pp. 121 126.

[21] Syahputra, R., Soesanti, I. (2016). Power System Stabilizer Model Using Artificial Immune System for Power System Controlling. International Journal of Applied Engineering Research (IJAER), 11(18), pp. 9269-9278.

[22] Jamal, A., Syahputra, R. (2016). Heat Exchanger Control Based on Artificial Intelligence Approach. International Journal of Applied Engineering Research (IJAER), 11(16), pp. 9063-9069.

\section{Authors' information}

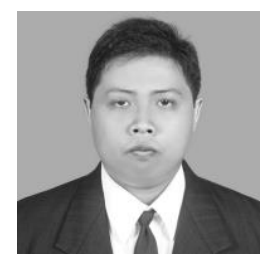

Rama Okta Wiyagi Received B.Sc degree from Department of Electrical Engineering Universitas Muhammadiyah Yogyakarta in 2009, M.Eng. degree from Department of Electrical Engineering and Informatics Technology, Universitas Gadjah Mada, Yogyakarta, Indonesia in 2014. Rama Okta Wiyagi, M.Eng. is a Lecturer in Department of Electrical Engineering, Faculty of Engineering, Universitas Muhammadiyah Yogyakarta, Indonesia. His research interests are in robotics, robotics vision and instrumentation.

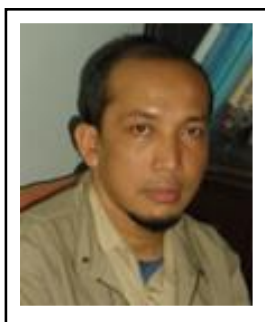

Ramadoni Syahputra received B.Sc. degree from Institut Teknologi Medan in 1998, M.Eng. degree from Department of Electrical Engineering, Universitas Gadjah Mada, Yogyakarta, Indonesia in 2002, and Ph.D degree at the Department of Electrical Engineering, Faculty of Industrial Technology, Institut Teknologi Sepuluh Nopember, Surabaya, Indonesia in 2015.

Dr. Ramadoni Syahputra is a Lecturer in Department of Electrical Engineering, Faculty of Engineering, Universitas Muhammadiyah Yogyakarta, Indonesia. His research interests are in computational of power system, artificial intelligence in power system, power system control, the application of fuzzy logic in power system, optimization, distributed energy resources, and renewable energy. 